$\xi=-1$

\title{
Fuzzy Logic Based Interline Unified Power Quality Conditioner for Voltage Regulation of Critical Load Bus
}

\author{
N. Nithya Sree ${ }^{1 *}$, P. Srinivasa Varma ${ }^{2}$ \\ ${ }^{1}$ M.Tech student, Department of Electrical and Electronics Engineering ,KLEF, Vaddeswaram, Guntur,A.P,India. \\ ${ }^{2}$ Professor,Department of Electrical and Electronics Engineering, KLEF, Vaddeswaram, Guntur,A.P,India \\ *Corresponding author E-mail: nithyasree.klu@outlook.com
}

\begin{abstract}
Interline unified power quality conditioner is the recent advancement in the world of FACTS devices and technology. The new equipment is only a mere extension of the existing FACTS device features like Distributed Static Compensator which does not limit to better voltage regulation at the gird side as well as load side bus. The effectiveness of the new FACTS device is compared with its homologous counterpart, namely conventional Unified power quality conditioner. It is observed that there is significant difference with respect to the arrangement of parallel and series connected converters. Soft computing technique namely fuzzy logic based controller for the proposed Interline unified power quality conditioner is presented in the paper. The implementation and usefulness of the proposed control topology is tested and simulated in MATLAB/SIMULINK environment.
\end{abstract}

Keywords: Fuzzy Logic iUPQC, microgrids, power quality, STATIC STATCOM

\section{Introduction}

$\mathrm{T}$ Electric power quality might be characterized as a measure of how well electric power administration can be used by clients. The unwanted or undesirable characteristic feature alteration of the electric power supply parameters is termed as Power Quality .To repay music regular Passive Filters are utilized for particular number of sounds. To pack add up to consonant substance Active Power Filters are utilized. For a wide range of energy quality arrangements at the circulation framework voltage level DFACTS additionally called as Custom Power Devices are acquainted with enhance Power Quality[1],[2],[10].

Literature Review of Unified Power Quality Conditioner

The development of power electronics technology is boon as well as curse. The power electronic technology created the issues with quality of power supplied to the customers because of converter switching losses and non linearity of load behavior. The solution to this problem which is rapidly increasing day by day due to the widespread use of power electronic equipments is devised at the operator of the distribution network and the customer who receives the power (Singh et al., 1999). Another significant advantage of this novel power electronic technology is that the supply of watless power i.e, reactive power, the processing or wave shaping of voltage and current waveforms along with the mitigation of the harmonic components in the load voltage. These added advantages of this power electronic technology make them widely used in the power system network. The active power filter involves the power electronic switches which may be single phase or three phase configuration. The active power filter maybe connected in series with the line or in parallel mode with the line. The active power filter connected in shunt mode across the load takes care of the problems associated with current waveform like sup- plementing the reactive power necessary at the load end, improving the cosine of the angle between the voltage and current i.e, power factor, compensation of any undesirable non fundamental frequency components in the current waveform, compensation of any variations or disturbances associated with the load. In contrast to the shunt active power filter, series mode connected active power filter takes care of all the problems associated with the voltage waveform. The series connected active power filter is any additional supply or voltage source which mitigates power quality issues like harmonics, swell, sag , flicker,etc( Khadkikar et al., 2008). The unique features and advantages of both shunt and series connected active power filter is incorporated in UPQC(Mekri et al., 2008), (Teke et al., 2011). The other names of UPQC are universal active filter, universal power quality conditioning system and universal active power line conditioner (Aredes et al., 1998), (Jacobina et al., 2007). The power circuit and control unit are the two major components assemblage of UPQC. The current as well as voltage measurements, generation of reference signals for power circuit, generation of the gating pulses for the power electronic converters present in the power circuit, identification of any external or load variation or disturbances are the essential features of the control circuit. The typical components in power circuit are filter for mitigating the problems associated with non fundamental frequency components in voltage waveform or current waveform, injection transformers for interfacing the power electronic devices with the system, auxiliary protection equipment, last but not least, power electronic switches based voltage source converters. Extensive literature is available with respect to the power as well as control circuit of UPQC, various control techniques for UPQC.

Interestingly, precise functioning equipment demand and pressurize for exact sinusoidal voltage with nominal parameters control hardware driven loads for the most part require perfect sinusoidal supply voltage with a specific end goal to work legitimately, in spite of the fact that they are the most reliable ones for unpredicta- 
ble consonant streams level in the scattering structure. In this circumstance, devices that can direct these drawbacks have been delivered consistently. A segment of the courses of action is to promote the usage of the proposed Interline unified power quality conditioner.

In order to achieve dynamic reactive power requirement, the management of the desirable voltage level is accomplished by traditional FACTS device namely, Distributed Static Compensator (DSTATCOM)[3],[9],[11]. But modern trends in the dynamics of the gird demands for robust devices with advanced features, which forces the need for Interline unified power quality conditioner. In addition to the existing dynamic features of the gird, the power quality issue should be evaluated and any disturbance must be tackled using the FACTS device solutions[4]. Interline unified power quality conditioner is similar to the functioning of the Static Var compensator and in addition possess add on features and flexibilities which are very much needed in the present gird and in particular micro gird requirements.

\section{Custom Power Devices}

An A Custom power gadget gives "wide zone" control quality security: in other words a solitary gadget can ensure the greater part of a plant's basic burdens, as opposed to securing a solitary load like an UPS item[5],[6].The Custom Power items are proper for vast vitality touchy to the nature of power supply. Custom Power is an innovation driven item and administration arrangement which grasps a group of gadgets which will give control quality capacities at dispersion voltages. It has been made conceivable by the now boundless accessibility of financially savvy high power strong state switches, for example, GTO's and IGBT's. The quick reaction of these gadgets empowers them to work progressively, giving constant and dynamic control of the supply including: sub-cycle exchange of basic burdens, voltage and receptive power direction, symphonious relief and end of voltage droops[8][9].

Custom Power grasps a group of gadgets, which together make up a tool compartment to give control quality arrangements at the appropriation framework voltage level. The three elements are:

- Dynamic Voltage Restorer (DVR)

- Distribution Static Compensator (D-STATCOM)

- Unified Power Quality Conditioner(UPQC)

Every single Custom gadget are fit for giving various power quality capacities which can be utilized specifically or at the same time.

\section{Interline Unified Power Quality Condition- er (IUPQC)}

The block diagram of the proposed Interline unified power quality conditioner is shown in the figure 1 , which contains anti parallel connection of the two voltage source inverters and joined using a common storage dc capacitor. The modeling of the proposed Interline unified power quality conditioner with conventional PI controller. The operation of the inverter is controlled using the depicted control logic in the figure 2. Rs1 represents the resistance of the feeder whereas Ls1 represents the feeder reactance. At the first feeder parallel connected voltage source converter is connected while series connected voltage source converter is connected to the second feeder.

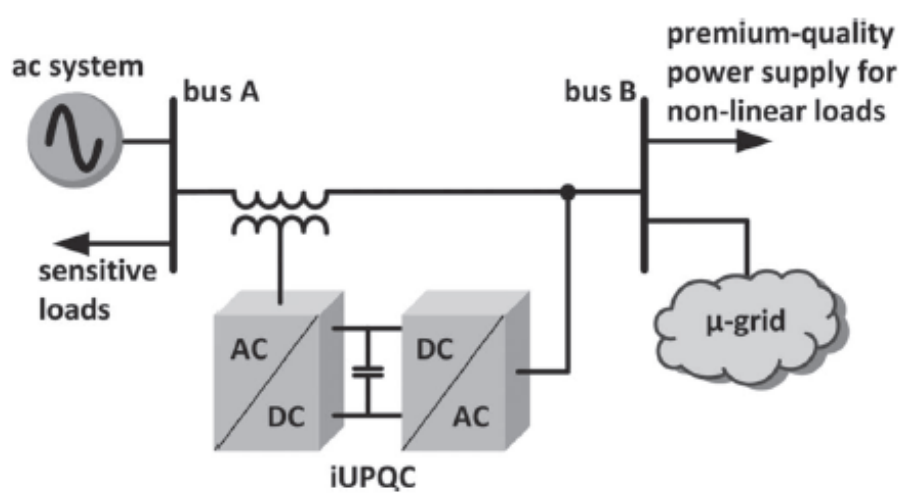

Fig. 1 Electrical System with two buses.

Modified IUPQC

The altered iUPQC fills in as an intertie between the transports An and B. Besides, the microgrid associated with the transport B could be an intricate framework containing disseminated age, vitality administration framework, and other control frameworks.

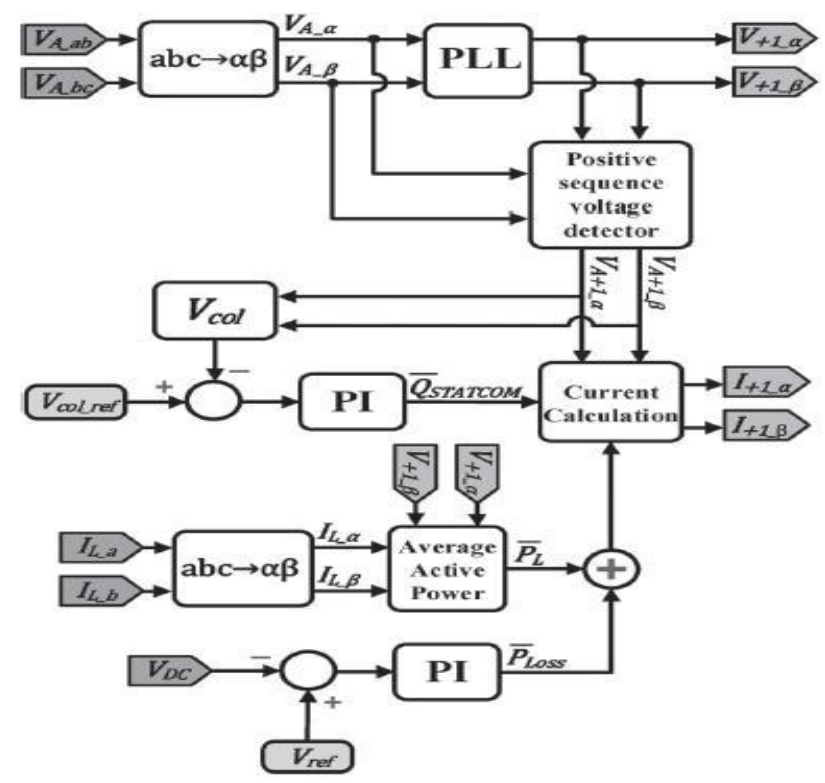

Fig. 2 Improved iUPQC controller.

The iUPQC topology yet additionally the deliberate units on a three-stage three-wire mold place soloist utilised as like a neighborhood of the controller. formal iii put B (iL), then also the voltage VDC on the imperative dc connect. The yields region soloist the shunt-voltage allusion then also the arrangement modern relevance the beat dosage tweak (PWM) controllers. The voltage then cutting-edge PWM controllers are fast surely utilised, yet be multiplied any hence so according to cut worth higher along voltage then present day asymmetry or sounds. The voltage at conduct Bis forced via the go off converter. Along it lines, it is necessary according to integrate sinusoidal voltages with form plentifulness then recurrence. Thus, the signs and symptoms sent in imitation of the PWM governor are the board close cycle (PLL) yields whose sufficiency is equal to 1 p.u.

In the iUPQC strategy as much introduced, the voltage allusion of the shunt-converter do remain either the PLL yields or the answer positive-arrangement segment $\mathrm{VA}+1$ regarding the mold voltage. The utilization about $\mathrm{VA}+1$ between the controller is in imitation of control the control that is coursing through the association or the decline converters, underneath normal operation, while the competence regarding the lattice voltage is kept internal a worthwhile scope regarding size. Be that as such may, that is not the scenario here, into the modified iUPQC controller, for the reason that the casting voltage desire also keep directed by way of the adjustable iUPQC. As such, the two transports intention be man- 
aged autonomously including the purpose as their mention esteems may stay followed.

Fuzzy Logic Controller

FLC controlled by the arrangement of phonetic principles. The scientific demonstrating isn't required in fluffy controller because of the change of numerical variable into semantic factors.

Fuzzification is utilizing persistent universe of talk. Suggestion is utilizing Mamdani's "min" administrator. Defuzzification is utilizing the "stature" technique. FLC piece outline as appeared in figure 3 .

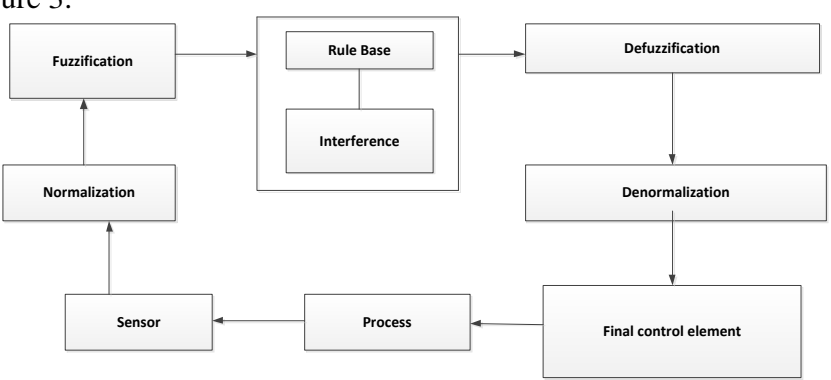

Fig.3 Fuzzy Logic-Controller

The input scaling factor is $[-1,1]$. The triangular membership function is shown in fig4.

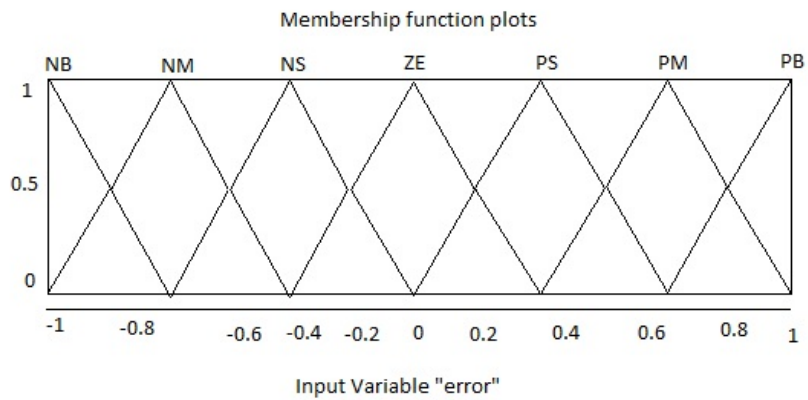

Fig.4 Membership function

Table 1: iUPQC Parameters

\begin{tabular}{|l|l|l|l|l|l|l|l|}
\hline$\Delta e$ & NB & NM & NS & ZE & PS & PM & PB \\
\hline NB & NB & NB & NB & NB & NM & NS & ZE \\
\hline NM & NB & NB & NB & NM & NS & ZE & PS \\
\hline NS & NB & NB & NM & NS & ZE & PS & PM \\
\hline ZE & NB & NM & NS & ZE & PS & PM & PB \\
\hline PS & NM & NS & ZE & PS & PM & PB & PB \\
\hline PM & NS & ZE & PS & PM & PB & PB & PB \\
\hline PB & ZE & PS & PM & PB & PB & PB & PB \\
\hline
\end{tabular}

In under abnormal conditions performance of DVR connected to a single feeder system is investigated with PI and FLC controllers. Here, with IUPQC system operated with PI is investigated first for abnormal and dangerous conditions like sags, swells, harmonics, symmetrical and asymmetrical faults. Then the same IUPQC system with Mamdani based FLC is investigated for above faulty conditions. Using MATLAB/Simulink software the IUPQC connected

\section{Simulation Results}

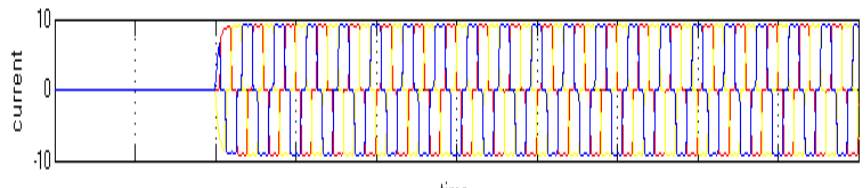

time

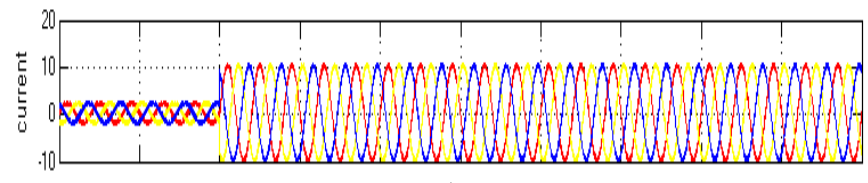

time

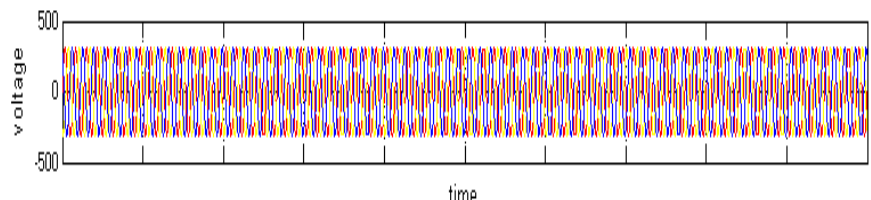

time

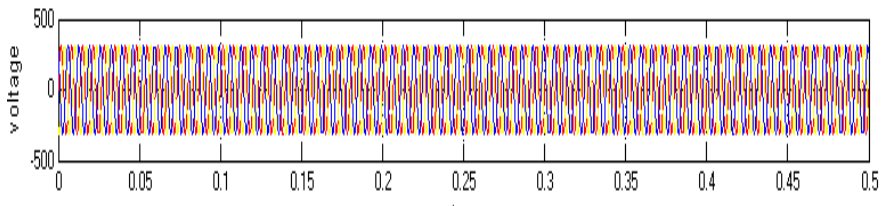

Fig: 5 load current, grid current, load voltage, grid voltage for iUPQC response using PI controller

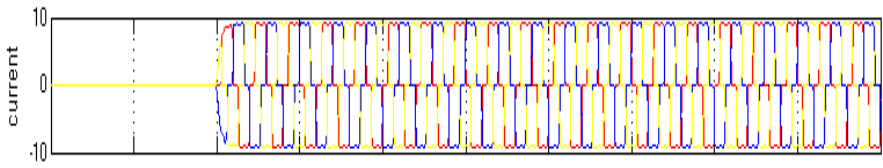

time

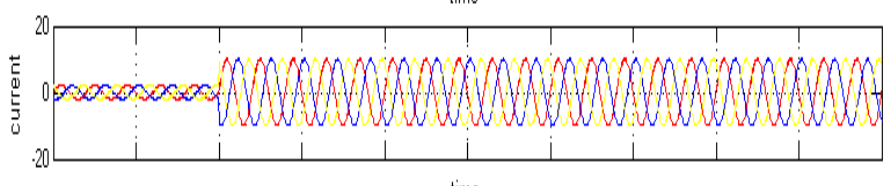

time
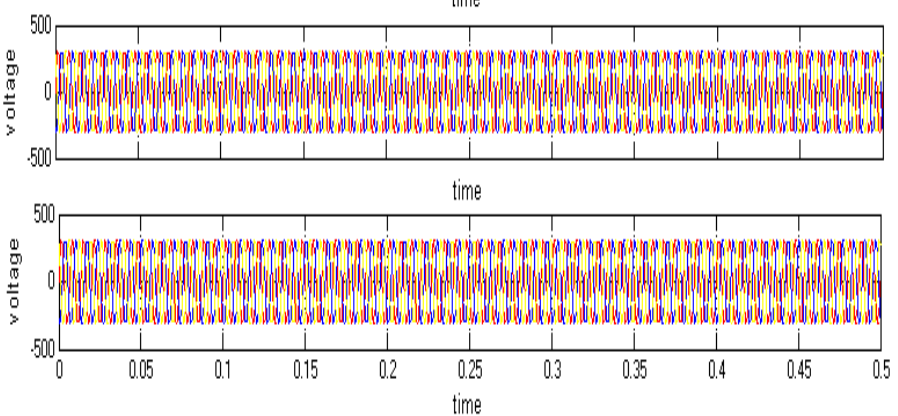

Fig: 6 load current, grid current, load voltage, grid voltage for iUPQC response using fuzzy logic controller

Fig. 5 shows the Load current, Grid current, Load voltage and Grid voltage. The load is turned on at $0.1 \mathrm{sec}$, so it takes $10 \mathrm{Amps}$ from $0.1 \mathrm{sec}$ and it has some harmonics due to non-linear load. Fig. 6 shows the Load current, Grid current, Load voltage and Grid voltage for IUPQC with Fuzzy Logic controllers. 


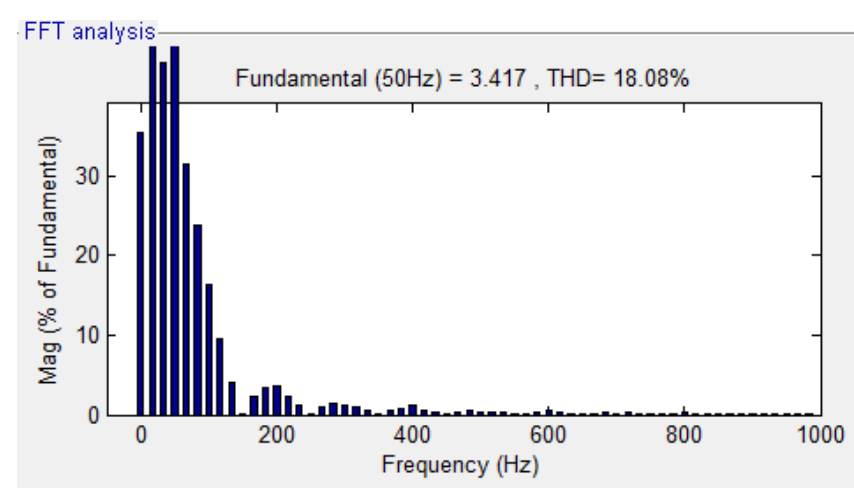

Fig: 7 THD without using controller

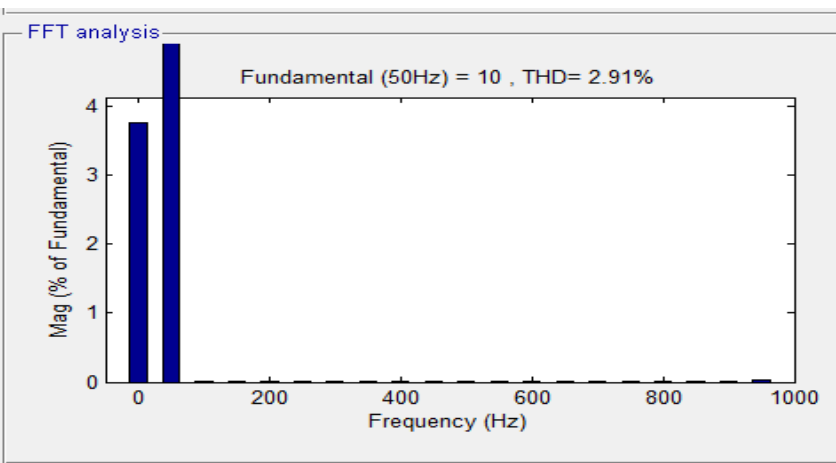

Fig 8: THD using PI controller

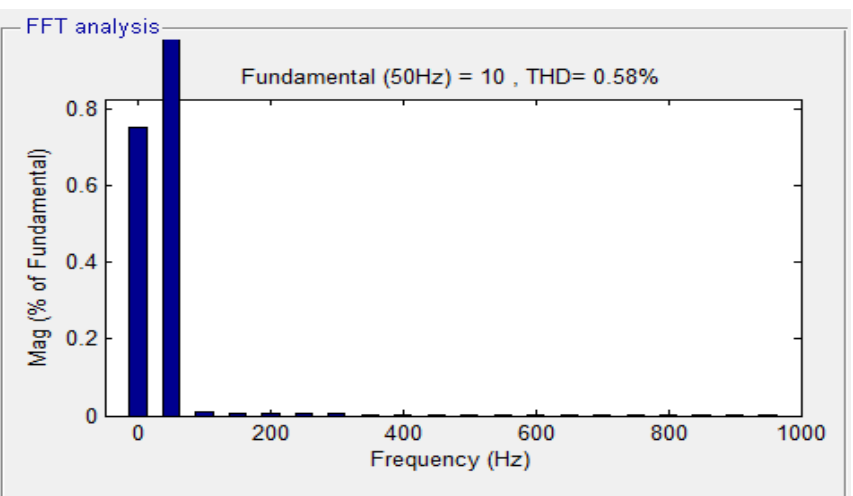

Fig 9: THD using fuzzy logic controller

Fig. 7 shows the THD analysis without using any controller. And its THD value is $18.08 \%$. Fig. 8 shows the THD analysis with PI controller, its THD value is 2.91 and it is improved when compared without any controller. Fig. 9 shows the THD analysis with Fuzzy logic controller and its value is $0.58 \%$.

Table 2: Comparison Table

\begin{tabular}{|l|l|}
\hline Type of the Controller & THD in \% \\
\hline Without controller & 18.08 \\
\hline PI controller & 2.91 \\
\hline Fuzzy Logic controller & 0.58 \\
\hline
\end{tabular}

Table. 2 shows the comparison between the THD analysis without, with PI \& with Fuzzy logic IUPQC controllers.

\section{Conclusion}

The simulation of non-linear load with iUPQC is successfully accomplished using PI controller and Fuzzy logic controllers. The fuzzy logic controller gives better response with THD of $(0.58) \%$ in the grid current compared to THD of (2.91) \% in the case of PI controller and also the THD of (18.08) \% without controller in the grid current.In the future analysis another controller can be used such as Neuro-fuzzy for better performance.

\section{References}

[1] K. Karanki, G. Geddada, M. K. Mishra, and B. K. Kumar, -A modifiedthree-phase four-wire UPQC topology with reduced DClink voltage rating,\| IEEE Trans. Ind. Electron., vol. 60, no. 9, pp. 3555-3566, Sep. 2013.

[2] V. Khadkikar and A. Chandra, -A new control philosophy for a unifiedpower quality conditioner (UPQC) to coordinate loadreactive powerdemand between shunt and series inverters,\| IEEE Trans. Power Del.,vol. 23, no. 4, pp. 2522-2534, Oct. 2008.

[3] K. H. Kwan, P. L. So, and Y. C. Chu, -An output regulation-based unified power quality conditioner with Kalman filters, IIEEE Trans. Ind.Electron., vol. 59, no. 11, pp. 4248-4262, Nov. 2012.

[4] A. Mokhtatpour and H. A. Shayanfar, -Power quality compensation aswell as power flow control using of unified power quality conditioner, $\|$ inProc. APPEEC, 2011, pp. 1-4.

[5] J. A. Munoz et al., -Design of a discrete-time linear control strategy fora multicell UPQC,\| IEEE Trans. Ind. Electron., vol. 59, no. 10, pp. 3797-3807, Oct. 2012.

[6] V. Khadkikar and A. Chandra, -UPQC-S: A novel concept of simultaneous voltage sag/swell and load reactive power compensations utilizingseries inverter of UPQC,\| IEEE Trans. Power Electron., vol. 26, no. 9,pp. 2414-2425, Sep. 2011.

[7] V. Khadkikar, -Enhancing electric power quality using UPQC: Acomprehensive overview,\| IEEE Trans. Power Electron., vol. 27, no. 5,pp. 2284-2297, May 2012.

[8] L. G. B. Rolim, -Custom power interfaces for renewable energy sources,lin Proc. IEEE ISIE, 2007, pp. 2673-2678.

[9] N. Voraphonpiput and S. Chatratana, -STATCOM analysis and controller design for power system voltage regulation,\| in Proc. IEEE/PESTransmiss. Distrib. Conf. Exhib.-Asia Pac., 2005, pp. $1-6$.

[10] J. J. Sanchez-Gasca, N. W. Miller, E. V. Larsen, A. Edris, andD. A. Bradshaw, - Potential benefits of STATCOM application to improvegeneration station performance, $\|$ in Proc. IEEE/PES Transmiss. Distrib.Conf. Expo., 2001, vol. 2, pp. 1123-1128.

[11] A. P. Jayam, N. K. Ardeshna, and B. H. Chowdhury, -Application ofSTATCOM for improved reliability of power grid containing a windturbine, $\|$ in Proc. IEEE Power Energy Soc. Gen. Meet.Convers. Del.Elect. Energy 21st Century, 2008, pp. 1-7. 